\title{
“Teaching, my passion; publishing, my pain": unpacking academics' professional identity tensions through the lens of emotional resilience
}

\author{
Shanshan Yang ${ }^{1} \cdot$ Dingfang Shu ${ }^{1} \cdot$ Hongbiao Yin $^{2}$ \\ Accepted: 6 September 2021 /Published online: 22 September 2021 \\ (C) The Author(s), under exclusive licence to Springer Nature B.V. 2021
}

\begin{abstract}
In the global competition of higher education, an increasing emphasis has been placed on university research excellence. Accordingly, academics have to engage in both research and teaching activities. The multiple and fragmented identities of academics can sometimes be contested, leading to identity tensions, and impeding their professional development. This raises the issue of how, and whether at all, academics integrate their professional identities in a culture of performativity. Against this backdrop, this qualitative study explored how a specific group of Chinese academics negotiate identity tensions as teachers and researchers through an emotional resilience lens. The narrative frames and interviews with 10 college English teachers yielded four types of identity negotiation in the continuum from identity conflicts to identity integration mediated by emotional resilience, including the disheartened performer, the miserable follower, the strenuous accommodator, and the fulfilled integrator. Emotional resilience as a mediator in professional identity tensions is discussed. Our findings offer a nuanced understanding of the complexity of academics developing an integrated professional identity. Policymakers should recognize the potential of emotional resilience in integrating academic professional identities and jointly support academics to cope with their identity tensions. However, if identity tensions are too complex for academics to solve, the policymakers should consider tensions as signals that the existing institutional policies may be counterproductive and need to be revised, rather than merely calling on academics' resilience.
\end{abstract}

Keywords Identity tensions · Professional identities · Emotional resilience $\cdot$ Performativity Academics $\cdot$ College English teachers

Hongbiao Yin

yinhb@cuhk.edu.hk

1 School of English Studies, Shanghai International Studies University, Shanghai, China

2 Department of Curriculum and Instruction, Faculty of Education, Chinese University of Hong Kong, Hong Kong SAR, China 


\section{Introduction}

Abundant literature discusses academic identity and highlights its importance (Carter 2020; Kreber 2010; Smith et al. 2016). In a changing higher education context, however, modern academic identities become contested and highly fragmented (Shams 2019). To raise universities in national or global rankings, promotion of research capability and productivity is on the agenda of nearly all universities around the world (Dai et al. 2021). The institutional privileging of research over teaching has become a site of academic identity tension internationally (McCune 2021). In teaching-focused institutions in particular, academics face challenges to meet the demands and expectations as active researchers, in addition to their role as university teachers. Identity tensions arise due to misalignment between professional and performative identity demands (Dugas et al. 2020; Siekkinen et al. 2020). Although tensions are inherent in academics' extended roles (van Winkel et al. 2018), how academics negotiate their multiple and sometimes contradictory identities, cope with tensions, and (hopefully) achieve a more integrated professional identity has received insufficient attention in the literature (Shams 2019).

As suggested by Peseta and Loads (2016), there are two directions in the landscape of academic identity research. One focuses on the disaggregation of academic work, unavoidably leading to fragmentation and anxiety. When it comes to identity tensions, we can study how the tensions militate against the development of academics' professional identities (Kaasila et al. 2021). Notably, the process of coping with change is emotionally laden (Chubb et al. 2017), and the emotions serve as meaningful ways to approach academic identities and their responses to change (Tran et al. 2017). Whereas the significant role of teacher emotion in the formation of professional identities and experience of tensions has been extensively studied in the school context (Lee and Yin 2011), emotions of academics regarding professional identity tensions have less often been addressed. Since the teacher identities of academics may differ significantly from the identities of schoolteachers (Kassila et al., 2021), it is critical to examine how emotional experiences inform the way academics negotiate their identity tensions. Changes in higher education pose not only threats but also opportunities for academics (Billot 2010). Thus, the other direction of academic identity research addresses how to hold teaching and research (and sometimes administration) coherently together. With respect to identity tensions, together with academics' resolutions or reflexivity, a more integrated professional identity can be achieved (Arvaja 2018; Kassila et al., 2021). To continue the conversation raised by Smith et al. (2016), we focus on the emotional responses that identity tensions cause, and more importantly on the resilience with which academics turn adversity into an advantage.

Resilience, as a complex, dynamic, and multidimensional phenomenon, can be conceptualized as the process of, capacity for, or outcome of positive adaptation and ongoing professional commitment and growth in the face of challenging circumstances. Different theoretical lenses focus on different aspects of this complexity. Despite the ongoing debate regarding the exact meaning of resilience, emotion is commonly emphasized in pertinent discussion. Emotional resilience in this study refers to academics' capacity to bounce back, to thrive amid identity tensions, and to construct integrated professional identities despite emotionally challenging circumstances. Existing studies that focus on the construction of professional identities in higher education contexts (e.g., Huang and Guo 2019; Kaasila et al. 2021), however, do not explicitly address the connection among academics' emotion, emotional resilience, and the negotiation of identity tensions. This study aims to contribute to this under-explored relation 
by offering a detailed account of how academics (i.e., 10 college English teachers in China) reconceptualize their professional identities by negotiating their role as teachers and researchers in a challenging context through the lens of emotional resilience. Within the specific context of the study, we asked the following two research questions: (1) How do academics negotiate their professional identities as both teachers and researchers? (2) What role does their emotional resilience play in the negotiation of professional identity tensions?

\section{Literature and conceptual framework}

This section starts with an overview of research on academic identities, arguing for a complex dynamic system approach that offers an integrative perspective from which to examine the negotiation of the sub-identities of academics. It proceeds to review studies on identity tensions, inherent in multiple identities and emotionally loaded, and how academics cope with tensions. It proposes that emotional resilience should be utilized as a lens to explore identity tensions. The section ends with a summary of initiatives in China that are directed at increasing research excellence and contextualizes the study within a specific group of Chinese academics.

\section{Conceptualizing academic identities}

Identity is a long-standing but debated topic in higher education research (Henkel 2005). Kreber (2010) distinguishes the psychological, social, and post-structuralist perspectives in studying identity. Arguably, these perspectives have complementary but distinctive strengths. The psychological stance is particularly informative regarding the specific content of identities, such as self-awareness, values, and beliefs, but it may attend less to the rich and dynamic nature of identity processes (Kaplan and Garner 2017). The socio-cultural perspective informs us of the contextualized nature of identity and the role of structural features of the individual's overall identity and the generalized processes of its formation, but ignores the content of those identities. The post-structuralist perspective prefers the notion subjectivities, emphasizing subjects' multiple and fluid identities and positionalities. Viewed in this way, however, academics' identities cannot be analyzed as a continuity of experience (Yang et al. 2021).

In this study, we conceptualize identity as a complex dynamic system anchored in action that comprises the actor's beliefs, goals, self-perceptions, and perceived action possibilities in the role (Kaplan and Garner 2017). The integrative nature of identity and its development from this perspective enables us to consider teacher and researcher identity as sub-identities of academics (Trautwein 2018) and explore professional identity by taking a holistic view (Kaasila et al. 2021). The integration of sub-identities will then lead to personal coherence, high commitment to and motivation in the roles, and overall well-being, while a lack of integration will trigger negative emotions, personal dilemmas, and diminished motivation (Garner and Kaplan 2019). Academics incessantly negotiate and strive to resolve identity tensions (Shams 2019) with regard to elements, components, and disintegration in identity systems. The negotiation reflects the academics' identity formation processes, involving a dynamic interaction between the structure that introduces new content and scaffolds change in interrelations and the agency of academics who purposefully take part in exploring their identities (Garner and Kaplan 2019). During identity negotiations, academics' emotions interact with their identity development (Yang et al. 2021) and help to express whether these sub-identities are in competition or are harmonized and balanced. 


\section{Professional identity tensions}

Tensions occur when academics are pursuing to integrate distinct aspects of their work to be able to perform in a changing environment with varying expectations (Siekkinen et al. 2020). Multiple and fluid identities (Shams 2019; van Winkel et al. 2018), including academics as teachers, as researchers, and sometimes as administrators, tend to be fragmented and contested (Huang and Guo 2019). The existing literature discusses identity tensions in two main ways. First, a limited number of studies are concerned with the integration of the teacher role into the identity of beginning academics. For example, in the study by van Lankveld et al. (2017), significant tensions are experienced by the beginning medical teachers because teaching is perceived by others as a low status occupation, but some with resilience manage to resist the negative associations. Second, most studies deal with the tensions around combining the teaching and research roles, involving internal struggles between personal and professional aspects of the self (McNaughton and Billot 2016) or misalignment between the professional self and the work context (Arvaja 2018; Dugas et al. 2020; Shams 2019). The increasing emphasis on research productivity in institutions which have traditionally focused on teaching excellence, for instance, leads to tensions regarding whether the primary academic identity is a researcher or a teacher (Dugas et al. 2020). In addition, misaligned institutional research policies and practices (van Winkel et al. 2018) as well as a misfit between the professional ethos and the organization's market driven requirements (Shams 2019) create conflicting identity demands.

Regarding academic identity, Ursin et al. (2020) pointed out that balanced or tensioned relations between research and teaching are emotionally laden. Moreover, Chubb et al. (2017) found that personal, moral, and disciplinary identities aligned with research policy result in positive and productive emotions, while misalignment causes emotional dissonance. Chubb et al. continue to emphasize the importance of including emotion in the academy for a more socially and morally coherent response to research policies. Nevertheless, emotion is largely implicit in the discussion of identity tensions in higher education contexts. Only a small number of studies (Chubb et al. 2017; Ursin et al. 2020) have explicitly set out to examine academics' emotional reactions and identities in response to the managerial practices. Even fewer studies, however, have explored the potential of emotion for understanding professional identities and the negotiations in a challenging context. Kaasila et al. (2021) mentioned that the relationship between positive emotions and cognition seems to be central to the development of academic teacher identity. Considering the significant role of emotion in professional identity development (Yang et al. 2021) as well as academics' experience of tensions, there is a need to explore academics' emotional reactions and their influences on identity tensions.

As illustrated by Shams (2019), how academics cope with identity tensions has received insufficient attention. Arvaja (2018), by drawing upon a dialogical approach, discusses the role of inner tensions and conflicts in making sense of one's professional identity. The author concludes that identity tensions together with resolutions lead to a more integrated professional identity. Kassila et al. (2021), on the other hand, found that a developmental project and reflexivity facilitated the development of more holistic, relational identities of academics. The tensions and synergies between different facets of academics' identities were shown to be important (McCune 2021). In this study, we are more concerned with how academics strive to balance the conflicting identity demands (Shams 2019). Our concern directs our attention to the emotions that identity tensions cause and, more importantly, to the emotional resilience with which academics turn adversity into an advantage. 


\section{Emotional resilience as the lens to investigate academics' identity tensions}

Given its close association with teachers' sense of identity and emotions (Beltman and Poulton 2019), we propose that resilience is a valuable lens to understand academics' negotiation of identity tensions. Since professional identity tensions are found to be accompanied by unpleasant emotions (Shams 2019), how academics manage these emotions serves to inform identity negotiations. The concept of resilience is located in the discourse of teaching as an emotional practice. For one thing, emotions constitute one dimension of resilience as teachers use strategies to maintain their commitment and well-being (Beltman and Poulton 2019). Simultaneously, emotions play a key part in the processes of building and sustaining resilience. Positive emotions in particular fuel and promote resilience. For another, resilience may play an indispensable role in the process of emotional experiences. Regarding these intricately woven constructs, the capacity of emotional resilience is essential for academics because they draw upon this capacity to maintain a sense of integrated professional identity. In this study, we view becoming and being academics in a performative culture as comprising constant negotiations between teacher identity and researcher identity (Garner and Kaplan 2019), interacting with emotional resilience, and being influenced by personal, institutional, and sociocultural factors. Before we unfold the research methodology of this study, the contextual demands on and role expectations of academics in China will be reviewed and discussed in more depth in the next section.

\section{Chinese academics in a performative culture}

In a worldwide performative and managerial culture, research excellence is emphasized across different contexts (Shin et al. 2014). To enhance the quality of higher education and to promote global competitiveness, a series of initiatives has been launched in China, including Project 211, Project 985, and Project Shuang Yiliu for the building of world-class universities. Chinese universities are reforming their policies regarding faculty's performance evaluation and promotion criteria and are increasingly putting in place more stringent requirements regarding their faculty's research output (Dai et al. 2021). Against this backdrop, academics, including college English teachers, have little choice but to assume the new identity as researchers due to pressure from the promotion review system that prioritizes research over teaching and other responsibilities (Xu 2014). Managerial professionalism with a focus on performance and accountability implies tensions and contradictions in academic work (Shams 2019). Concurrently, the culture of performativity might be an opportunity for academics to balance external accountability with their development needs. Therefore, it is necessary to explore how academics grapple with the tensions and how they manage to integrate the two sub-identities.

College English is a compulsory course for non-English major undergraduate students in China. It is generally composed of courses aiming to improve students' English proficiency. Most academics lecturing college English are Chinese, with a small number of native speakers of English teaching listening and speaking courses in some universities. As the largest group of tertiary teachers in China, approximately 60,000 college English teachers lecture nearly 16 million students each year (Zeng and Fickel 2021). Most college English teachers usually hold MA or MEd degrees, with a relatively few but gradually increasing number holding doctoral degrees. The majority of college English teachers have not received sufficient pedagogical training before employment. The reasons we chose college English teachers are as follows. 
First, college English departments have long been viewed as service departments rather than academic units (Zeng and Fickel 2021). Traditionally perceived as craftsmen in teaching, college English teachers encounter intense pressure around becoming legitimate academic citizens within Chinese higher education. Second, these academics lack research incentives, skills, and capacities compared with cohorts in other disciplines. They are in a disadvantaged position in terms of promotion to higher ranks considering the limited quota for promotion and are therefore in a vulnerable position in terms of surviving in the current competitive higher education system. Third, the research-output-oriented institutional obsession constitutes a major source of tension and dilemma for college English teachers (Huang and Guo 2019). The shifting focus from language teaching to research may conflict with college English teachers' commitment to and investment in teaching.

Research and publishing increasingly dominate academics' professional lives. The evidence is largely consistent in revealing that college English teachers experience tensions and identity conflicts amidst a heavy workload and inadequate award scheme. While some seemed to feel vulnerable and powerless, others were fueled and empowered to engage in and publish research as they responded to the external demands ( $\mathrm{Xu}$ 2014). Thus, it is imperative to investigate how college English teachers make sense of, feel, and solve professional identity tensions to better understand academics' identity construction and professional development.

\section{Methodology}

For more insightful and ingrained data, this study employed a qualitative approach making use of narrative frames and in-depth interviews. They are viewed as complementary methods $(\mathrm{Xu}$ 2014) because narrative frames can be used both as a preliminary instrument for data collection and a verification tool for findings from in-depth interviews (Barkhuizen 2014). The choice and sequencing of methods aim to triangulate and ensure the validity of the study (Ravitch and Carl 2019).

A narrative frame refers to a written story template in which the participants are given prompts to produce a coherent story according to their experiences and reflections (Barkhuizen 2011). A sample narrative frame is as follows: "I do academic research because... Towards which, I feel..." To elicit meanings that storytellers make of their experiences (Barkhuizen 2014), we adapted Xu's (2014) narrative frames which covered institutional requirements and policies for research, engagement with research, motivation for and attitudes towards research, and perceived challenges and solutions. Due to the focus of the current study, we also asked about academics' emotional experiences and possible reflections for each theme. Moreover, the perceived relationship between teaching and research was added in our narrative frames. The adjustments aimed to reach a fuller understanding of the academics' emotional responses to their research engagement and identity negotiation. As suggested by Barkhuizen (2014), we made use of Web $2.0^{1}$ technologies by inviting participants to complete the narrative frames via WeChat ${ }^{2}$ through which the research team and the participants could interact before, during, and after the completion.

\footnotetext{
${ }^{1}$ Rather than simply accessing information, Web 2.0 sees the internet as a medium for interactive experiences, in the shape of blogs, wikis, social platforms, etc.

${ }^{2} \mathrm{~A}$ leading messaging and social media app in China.
} 
Based on preliminary data from the narrative frames, we conducted a series of semi-structured in-depth individual interviews (Seidman 2006) to explore the academics' life history, their emotional experiences at work, and possible reflections. In this way, it was feasible for participants to talk freely and candidly about emotionally loaded topics (Cohen et al. 2011). The participants were first asked to tell their history of English learning and teaching as well as the emotional experiences in their professional lives. Then they were invited to reflect on the meaning of their experiences (Seidman 2006). The interviews share key questions and pursue customized replication through individualizing follow-up questions and probes both from their previous narrative frames and within each interview (Ravitch and Carl 2019). Key questions about aspects of their professional lives they enjoyed the most or least were asked because, as the academics talked about their identities as language teachers and researchers, the emotional reactions to respective identity naturally emerged. Restricted by the stay-at-home policy during the global COVID-19 pandemic, the interviews were conducted by telephone and social media platforms. Participants and researchers stayed in touch using WeChat for clarification or further explanation.

\section{Participants}

A purposeful sampling strategy (Spradley 1979) was used to select 10 college English teachers from a range of public universities. To achieve maximum variation sampling, which Seidman (2006, p. 52) referred to as "the most effective basic strategy for selecting participants for interview studies," the study recruited participants with varied years of teaching college English, qualifications, and academic ranks from differentiated institutional levels across China (see Table 1).

\section{Data collection}

Data were collected from narrative frames filled out by the 10 college English teachers and subsequent interviews with each of them. We first contacted potential participants, explained our research purpose and methods to them, and ensured confidentiality with their personal information. Gaining consent of their participation, we sent the narrative frames in an editable file via WeChat to create opportunities for the participants to respond without time or space limitations. After collecting the frames, interviews were arranged at their convenience. The first author conducted the semi-structured interviews in a conversational and relaxing way, allowing the interviewees to speak freely, and encouraging new topics to emerge organically in the interview conversations. All the interviews, each lasting around one hour, were audio-recorded and transcribed verbatim on a speech recognition platform (https://www. iflyrec.com) and checked by the first author for further analysis. As recommended by Ravitch and Carl (2019), participant validation strategies were utilized throughout the research process, including engaging participants in determining accuracy and sustained dialogue over time.

The experiences of being a former college English teacher allowed the first author to gain an insider view, providing insights otherwise unavailable to the external researchers. Living in the same context and experiencing academic rank promotion herself, she could identify with their challenges. The researcher's positionality as an insider was most likely the reason why the participants were willing to share intimate details about their stories and emotions with her. 


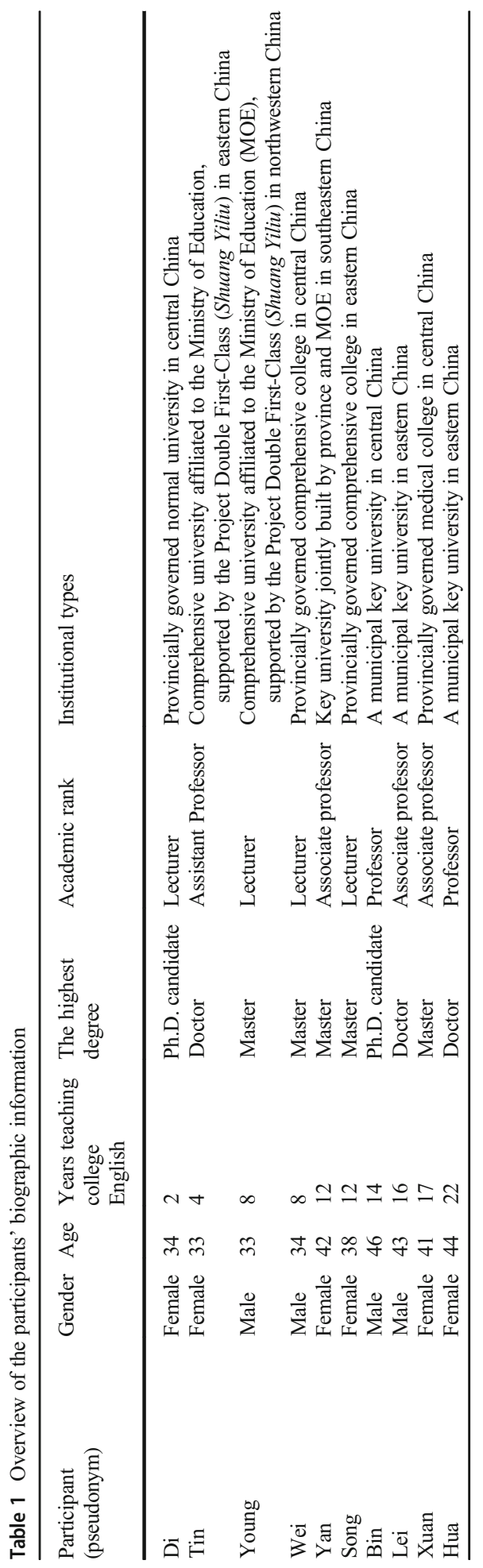




\section{Data analysis}

Data analysis comprises both inductive and deductive coding processes (Ravitch and Carl 2019). The first two authors inductively conducted iterative cycles of open coding and recoding across the data set and kept modifying potential themes which emerged from the analysis. During the analysis, the coders regularly discussed the progress and reached a high level of congruence of coding. While the inductive procedures allowed the themes to emerge from the data regarding academics' identity negotiations and influencing contexts, we applied the pre-existing constructs to ground the data analysis. The coding system finalized in this study is shown in the Appendix Table 3.

Based on Garner and Kaplan's (2019) conceptualization of interaction of sub-identities triggering emotions, Figure 1 visualizes the interaction among professional identities, emotions, emotional resilience, and influencing factors. This visual schematization of the relationships among the major constructs was used to guide our data analysis. The analysis process incorporated multiple readings of both the frames and interview data to achieve immersive engagement (Ravitch and Carl 2019). In vivo codes were applied whenever the participant's language accurately captured what was expressed (Ravitch and Carl 2019). The data analysis revealed that the content fell into two major themes: identity integration and identity conflicts.

Table 2 illustrates the coding categories on the participant teachers' perceived tensions, emotions, and identity negotiations evidenced by in vivo codes. To assure the validity and trustworthiness of the study, we adhered to data triangulation and researcher triangulation (Patton 2015). We used a combination of two data sources, namely interviews and narrative frames, which displayed consistent findings. The first two authors coded the data and formed preliminary interpretations independently. Afterwards, the interpretations were discussed until a consensus was reached concerning the final interpretations. The third author then provided

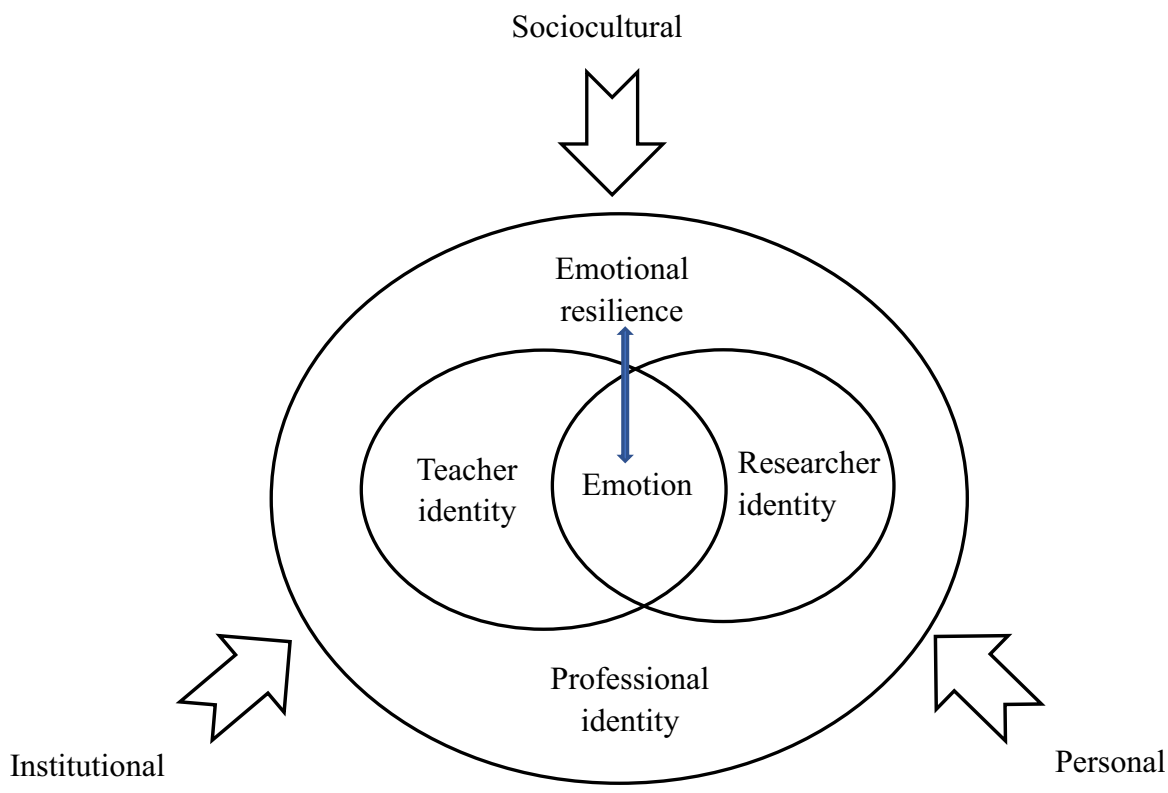

Fig. 1 Professional identity of academics 
Table 2 Professional identities and teachers' emotional reactions

\begin{tabular}{|c|c|c|c|}
\hline Categories & Perceived tensions & Emotions & $\begin{array}{l}\text { Exemplary identity } \\
\text { negotiations }\end{array}$ \\
\hline $\begin{array}{c}\text { Disheartened } \\
\text { performer }\end{array}$ & $\begin{array}{l}\text { Low self-efficacy; mental \& } \\
\text { physical health }\end{array}$ & $\begin{array}{l}\text { Unhappy; no sense of } \\
\text { achievement }\end{array}$ & $\begin{array}{c}\text { Teacher identity is in tension } \\
\text { with researcher identity }\end{array}$ \\
\hline $\begin{array}{l}\text { Miserable } \\
\text { follower }\end{array}$ & $\begin{array}{l}\text { Limited time \& energy; } \\
\text { unreasonable institutional } \\
\text { research policy; multiple } \\
\text { professional role } \\
\text { expectations; heavy } \\
\text { teaching load; demanding } \\
\text { research task; difficulty in } \\
\text { publishing in core journals }\end{array}$ & $\begin{array}{l}\text { Powerless; lost, sad, and } \\
\text { helpless; miserable, } \\
\text { anguished, afflictive, lost, } \\
\text { and confused; feel really } \\
\text { ashamed... feel like an } \\
\text { incompetent and } \\
\text { unqualified employee; } \\
\text { anxious }\end{array}$ & $\begin{array}{l}\text { I want to be an English } \\
\text { teaching expert, not just a } \\
\text { craftsman...but still, the } \\
\text { main task for college } \\
\text { teachers is to impart } \\
\text { knowledge and cultivate } \\
\text { people }\end{array}$ \\
\hline $\begin{array}{l}\text { Strenuous } \\
\text { accommo- } \\
\text { dator }\end{array}$ & $\begin{array}{l}\text { 'Publish or perish' culture; } \\
\text { unfair project review } \\
\text { process; unsupportive } \\
\text { institutional culture; } \\
\text { personality; insufficient } \\
\text { academic training }\end{array}$ & $\begin{array}{l}\text { Very happy; very miserable; } \\
\text { glad...satisfied ... happy; } \\
\text { strenuous; exhausted }\end{array}$ & $\begin{array}{l}\text { Only when we do research can } \\
\text { we transit from a } \\
\text { knowledge transmitter to a } \\
\text { research-oriented teacher }\end{array}$ \\
\hline $\begin{array}{l}\text { Fulfilled } \\
\text { integrator }\end{array}$ & $\begin{array}{l}\text { Tight research schedule; } \\
\text { heavy teaching load; } \\
\text { collegial pressure; } \\
\text { work-life balance }\end{array}$ & $\begin{array}{l}\text { All sorts of emotions... } \\
\text { Fulfilled; proud; shocked... } \\
\text { discontented; tired; } \\
\text { unsatisfied and upset; not } \\
\text { satisfied with myself }\end{array}$ & $\begin{array}{l}\text { Posit me as a } \\
\text { research-oriented teacher; } \\
\text { consider research and } \\
\text { teaching not opposite but } \\
\text { connected...likely to push a } \\
\text { teacher to grow }\end{array}$ \\
\hline
\end{tabular}

his views on the findings and interpretations. Whenever contradictory views emerged, all the authors discussed the issue to reach an agreement.

\section{Findings}

College English teachers in this study experienced identity conflicts regarding the aggregation of sub-identities (Trautwein 2018) and demonstrated varied capacities of emotional resilience, along with a rich landscape of emotions. The analysis uncovered themes of identity conflicts and identity integration, which are conceptualized as a continuum of professional identity negotiation. Based on common characteristics in their emotional resilience and negotiated identities, these academics were correspondingly classified into four types: the disheartened performer, the miserable follower, the strenuous accommodator, and the fulfilled integrator. This section provides three categories of portraits with weak, moderate, and strong emotional resilience respectively, to illustrate nuanced and contextualized understandings of and variations in the need for emotional resilience in managing the tensions in professional identities.

\section{The disheartened performer and the miserable follower with weak emotional resilience}

One disheartened performer (Lei) and three miserable followers (Hua, Song, and Young) were grouped into this category. They experienced identity conflicts, showed weak emotional resilience and encountered career bottlenecks while negotiating the two roles. 


\section{The disheartened performer}

Lei, a disheartened performer, was "unhappy about both teaching and research" with "no sense of achievement." Due to a shortage of English teachers, it was arranged that he filled this role although he had neither interest nor sufficient pedagogical training. Signs of burnout could be identified in such a statement as follows:

I don't like this job...nor good at it...I'm neither good at nor interested in English...

Lei has low self-efficacy. His belief in the teacher's limited role in students' language learning is deep-rooted. Moreover, he believes that existing research is impractical. These beliefs aggravated his identity tensions, containing a strongly negative emotional value. Consequently, he was detached from his professional identities and compromised with a so-called disheartened performer self-image:

Both research and teaching are hard for me. I think these two aspects are conflicting. Every academic is under pressure to produce research output, but physically I cannot bear intensive brainwork...I am indifferent to teaching now. I think the role for academics is just to finish teaching tasks. I really don't suit this occupation. All these years, I could not do it well. It is not possible for me to do it well now or in the future.

Two sub-identities are explicitly declared to be in tension, characterized by negative emotions, personal dilemmas, and diminished motivation (Garner and Kaplan 2019). Resilience happens when academics harness personal and contextual resources and use strategies to overcome challenges and maintain well-being (Beltman and Poulton 2019). However, Lei adapts negatively to the dilemma and states that he is powerless to change. As academics draw upon their capacity of emotional resilience to maintain a sense of integrated professional identities, it is natural that the disheartened performer can only live with tensions and dilemmas.

\section{The miserable follower}

For miserable followers, immense pressures from research and publishing are recurrent themes in their accounts. Consequently, strong negative emotions are reported. For example, one participant feels "exhausted" (Song) due to a heavy teaching load, demanding research tasks, and difficulty publishing in core journals. Perceiving bias against applicants without a doctoral degree or senior rank, she feels "lost, sad, powerless and helpless" concerning her failure in applying for research grants. The pressure is not limited to junior lecturers struggling with research due to academic rank. Another participant in her late career, holding a doctoral degree and professor title, still feels "miserable, anguished, afflicted, lost and confused" (Hua) because her belief in academic productivity as a professor's responsibility is in tension with her self-perception of being academically unproductive for the past 5 years, aggravated by collegial pressures. It is difficult to bridge the two roles:

I don't suggest college English teachers do research, ... (it is) useless to teaching and causes tensions in time and energy. (Young)

Subject to top-down mandates, academics must be research-engaged, but research seems to be undertaken as an isolated activity away from their daily practice (Xu 2014). Consequently, tensions in time and energy were perceived, ignoring the potential of research-informed teaching (Mathieson 2019). Song, for example, claimed to do research only for "utilitarian purposes," namely academic rank and salary increase. 
Academics in this category saw themselves primarily as language teachers, and prioritized teaching over research. They have no choice but to adjust their roles regarding external demands or expectations. External motivations, along with passive attitudes and negative emotions, denote weak emotional resilience and academics' vulnerability when confronting challenging contexts (Xu 2014). Academics identified no accessible resources to integrate research and teaching and encountered bottlenecks in their professional development.

\section{The strenuous accommodator with moderate emotional resilience}

Participants (Xuan and Di) in this category articulated frustration, confusion, and self-doubt stemming from scholarly publication required for promotion, and the unfair research grants application process. For instance:

Teaching is my passion, but publishing is my pain... strict demands for academic papers to get promoted...miserable. (Xuan)

Failure in publication and research grant application leads academics in institutions traditionally focused on teaching excellence to doubt their competence (Xu 2014). Their emotional responses revealed a lack of integration of professional identities. Regarding possible reasons for disintegration, Di remarked:

...young academics often fight alone, receiving no support from the department... slow progress and sometimes efforts in the wrong direction. (Di)

In an unsupportive and non-collaborative institutional culture, the integration of identities is a great challenge. However, they somehow recognized resources at their disposal with moderate capacities of resilience and enacted their agency to make efforts in the direction indicated by their emotions. One participant remarked:

One thing that promotes my personal growth is that I'm not satisfied with myself. When I reflect on my teaching and research, I find that I'm still deficient in many aspects. And that self-dissatisfaction turns out to be a drive for me to grow as well. (Di)

The strategies for the convergence of the two roles include doing a Ph.D. program or conducting action research combined with systematic reflection which could lead to professional growth (Nevgi and Löfström 2015). However, the road to integrating the two sub-identities is not smooth. Whereas one academic reported pleasure and satisfaction from doing action research, aligned with her belief in doing research to transform from "a knowledge transmitter" into "a research-oriented teacher" (Xuan), the other experienced shock and discontent in doing a Ph.D. program when she perceived a deficiency in academic training:

I was shocked to find that their research methods are nothing like ours... how to do the experiment, use the software, and analyze data. I didn't learn any of this in China. I am very discontented. It feels like starting from scratch. (Di)

Emotions are integral in the tensions, but academics do not avoid self-doubt or self-dissatisfaction. Rather, these negative emotions drive and direct their efforts to enact agency, as they stimulate a re-evaluation of current thinking and practices and the adoption of new ones. Overall, the strenuous accommodators go through identity conflicts but make efficient efforts to integrate the two identities, showing a moderate capacity for resilience.

\section{The fulfilled integrator with strong emotional resilience}

Four participants (Bin, Tin, Yan, and Wei) identified themselves as research-oriented and were grouped into the fulfilled integrators. Despite their overall positive attitudes towards their 
professional identities, still, a variety of emotions were expressed in statements such as the following:

With a tight schedule and heavy teaching load...very anxious. When other academics do a better job than me, I feel angry and low... (when I) get the funding, I am very happy. All sorts of emotions. (Yan)

The emotional rollercoaster Yan reported was collectively shared by other academics when talking about experiences as researchers (e.g., Chubb et al. 2017). To some extent, it reflects the adverse effects of the implementation of one-size-fits-all structures concerning research excellence (Siekkinen et al. 2020). Despite threatening circumstances, the fulfilled integrators manage to maintain effective functioning in their practice. These academics were fully conscious of the dual responsibilities of being college English teachers and believed in the mutual promotion of the sub-identities. The commonalities among these academics included their intrinsic motivation to do research in addition to external demands, their actions of linking teaching practice with research, and perceived emotional drive in integrating professional identities. Take Tin, an active researcher and academic writing teacher at an early career stage, as an illustrative example:

We can explore research questions from the teaching process. Then, we will not feel so tired and divided... teaching is not just imparting knowledge and educating people but also improving our competence and getting a promotion. (Tin)

Her goal of professional value and belief in teaching and research of mutual benefits aligned with her actions of linking publishing experiences with teaching practice, triggering an emotion of confidence as a beginning academic. The integration of two identities indicated congruency between traditional expectations of cultivating knowledge and educating people, and new institutional demands as active researchers, coupled with her professional aspirations. The integrated professional identity spared the teacher a sense of tiredness and division.

Academics in this category pinpointed the importance of positive emotions. For instance, Wei said "A sense of achievement can motivate an academic to teach better and do better research." Furthermore, those positive emotions they felt from one sub-identity influenced the other:

A sense of satisfaction in research will definitely affect my teaching... recognition in research will make me feel pleasant in every aspect and realize my potential in classroom teaching. (Wei)

The fulfilled integrators show a high level of emotional resilience, including emotional awareness and emotion regulation:

I must learn to regulate disappointment or frustration. Or else, it's harmful to us, physically and mentally. (Tin)

Despite the anxiety, sadness, and disappointment, I keep encouraging myself. All these experiences, success or failure, are unavoidable in our road of growth. (Yan)

They are aware of the harm of negative emotions and consciously use strategies, either through self-consolation, providing a different perspective in difficult situations, or changing the direction of their efforts, to restrain their negative emotions and focus on the positive ones. Embedded in the accounts of this group is an agentive sense of professional selves despite external constraints, such as inaccessible databases (Wei), oversized and heterogeneous classes (Bin), heavy workloads (Tin), and fluctuations in rewarding policies (Wei). The cultivation of emotional resilience requires continuous investment of professional and personal resources, such as intrinsic motivation, professional commitment, and agency. Apart from harnessing resources from within oneself such as thinking differently or self-calming, or from a personal support network of trusted colleagues or family members (Beltman and Poulton 2019), 
academics in this study also underlined the importance of leadership support and professional development programs for sustaining resilience. With high emotional resilience, they take initiatives to explore the possible ways to integrate seemingly conflictual identities. For example, Bin searched the academic database for existing studies to improve students' English writing, and Tin explored research questions from the teaching process.

\section{Discussion}

In the present study, the complexity of the professional identity of the academics was demonstrated in the ongoing negotiations between sub-identities (Trautwein 2018). It should be cautioned, however, that the prominence of teacher identity and researcher identity does not preclude the existence of others. We examined the emotions and emotional resilience of college English teachers as a lens to understand the negotiation of professional identity tensions in a challenging context in Chinese higher education. In answering the first research question, academics negotiate their professional identity tensions in a continuum from identity conflicts to identity integration. Regarding the second research question, emotional resilience serves as a mediator in the negotiation of identity tensions. There were fluctuations in and variations between academics' capacities to sustain emotional resilience in the face of professional identity tensions. Academics who are more emotionally resilient are more likely to solve identity tensions and integrate their professional identities. How emotional resilience mediates the negotiations of professional identity tensions and what other factors influence identity negotiations will now be discussed.

\section{Emotional resilience as a mediator in professional identity negotiations}

It is fair to say that most academics are bound to experience emotional challenges during their integration of sub-identities as described. One important aspect that differentiates the integrated and struggling academics is their capacities of emotional resilience and recognition of resources at their disposal which are influenced by factors at various levels (see Figure 2). In Figure 2, we visualize the degree of integration of professional identity by the area of intersection between teacher identity and researcher identity. The larger the area of intersection is, the more integrated the professional identity will be. We present four types of negotiated identities according to academics' capacities of emotional resilience and their professional identity negotiations. With weak emotional resilience, the disheartened performer reports negative emotions regarding both teacher and researcher identities. The two sub-identities are explicitly declared in tension, and teachers are unable to take actions and adapt positively to the perceived dilemma. The miserable followers, with weak emotional resilience as well, emphasize teaching over research and report strong negative emotions concerning contextual demands to conduct and publish research. The academics did not identify accessible resources to change and were thus unable to bridge the conflictual sub-identities. The strenuous accommodators consider teaching as their passion and publishing as their pain. With moderate emotional resilience, they recognize resources at their disposal and enact agency towards convergence of the two roles, directed by their negative emotions. The fulfilled integrators demonstrate strong emotional resilience in that the academics highlight positive emotions, recognize the harm of and thereby consciously regulate the negative emotions. Despite an emotionally challenging circumstance, they manage to integrate the sub-identities and thrive amid identity tensions. 

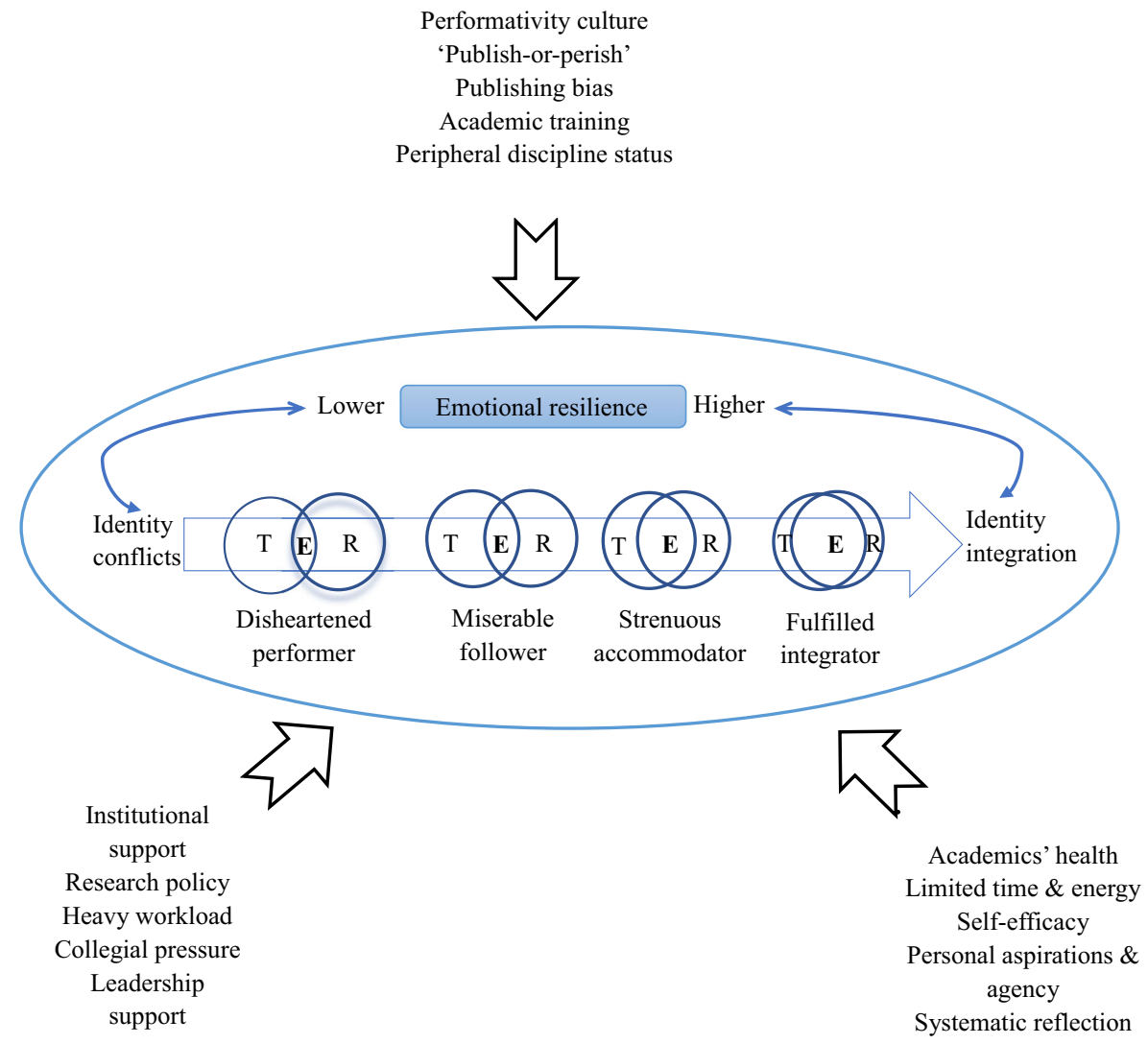

Fig. 2 Emotional resilience and the continuum of professional identity negotiation. Note: T stands for teacher identity; R stands for researcher identity; E stands for emotion

In tune with post-modernist standpoints (Henkel 2005; Castelló et al. 2021), we are aware of the dynamics and changes of academic identities. As academics face continuous changes and constantly interact with the sociocultural contexts, the negotiation among their multiple sub-identities is an on-going process (Billot 2010; Trautwein 2018). Therefore, the four types of identity negotiations are fluid and open to change. When circumstances change, in a performative and managerial culture for instance, the academics' identities might move towards more integrated or more conflictual identity types. We agree with Carter (2020) that transitions of academic identities are more nuanced than a clear dualism of either alignment with or separation from managerialism. The typology we present here is temporal and transitory based on findings from a cross-sectional study. We propose that further studies explore in a longitudinal vein in order to understand the issue more deeply.

In our discussion of emotional resilience as a mediator in professional identity negotiations, it seems that the strategies lie within the personal and micro-level realms of academics (Beltman and Poulton 2019). There is a need, however, to recognize that the sources of tension and stress in the managerial and performative culture are not 
necessarily within the academics' control. We need to avoid a deficit model that blames the academics for lacking personal resources (Beltman and Poulton 2019). Instead, we should view cultivating and sustaining resilience as a collective endeavor. Moreover, if identity tensions are commonly experienced by academics in institutions, the policymakers should seriously consider these as signals that the existing institutional policies may be counterproductive and need improvements, rather than merely calling on resilience on the part of academics.

\section{Influencing factors of professional identity tensions}

First and foremost, academics have to orient themselves towards externally defined criteria for success that the performative culture offers. In the "publish or perish" culture (Bai 2018), along with rigid institutional research policy (labeled as fluctuating, demanding, sometimes even unreasonable) and insufficient institutional support (Xu 2014), academics have to conduct research (restricted by insufficient academic training, heavy workloads, health, and limited time and energy), vie for research grants (via an unfair review process), and publish articles in core journals, confronting potential bias against authors without a doctoral degree or senior rank (Dai et al. 2021). With low self-efficacy and belief misaligned with institutional requirements, the academics are likely to go through identity conflicts. To echo Kreber's (2010) notion of the disciplines most strongly influencing academics' teacher identity, the inherent struggles these academics face reflect an uncertain and under-recognized status as college English teachers in the contemporary higher education system. These teaching-focused, public service-oriented academics occupy the bottom of the academic hierarchy (Zeng and Fickel 2021). They are not typically equipped with adequate knowledge and skills to undertake systematic inquiries and report their findings in academic journals, and a lack of integration triggers an overall negative emotional reaction and personal dilemmas (Garner and Kaplan 2019).

However, the experience of identity conflicts in performativity culture does not constantly lead to negative consequences. Several academics manage to grasp opportunities among challenges (Billot 2010) and integrate the two sub-identities. In addition to academics' capacities of emotional resilience, research interest (Mägi and Beerkens 2016), beliefs about the value of research (Bai 2018; Kaasila et al. 2021), and willingness to reflect (Nevgi and Löfström 2015) all play important roles in integrating the two sub-identities. If only extrinsically driven to do research, academics are unlikely to integrate research with daily practices (Xu 2014) in a sustainable way. When research is perceived as an effective strategy to generate evidence for teaching practice and professional growth, academics are more likely to be internally driven to do research, thereby creating opportunities for the integration of professional identities.

\section{Conclusion and implications}

The study offers a close-up investigation into the influences of performative culture in academics' emotions, emotional resilience, and their professional identity negotiations at a time of increased research emphasis. First, the findings illustrate that the 
neo-liberal practices of higher education have caused identity tensions for academics, who need to be aware of the adverse effects of performativity (Huang and Guo 2019) and enact agency to combine external demands with their own internal development needs. Second, the findings indicate that an understanding of the mutually reinforced relationship between research and teaching, an internal research interest, and the capacity of emotional resilience could promote academics to integrate the two identities. Therefore, balancing the two aspects of the academics' identities - one that reflects the assumed teacher identity to impart knowledge and educate people and the other representing the expected researcher identity to meet the institutional demands-should be addressed directly by training programs and professionals who support academics' development during their career span. Apart from providing support regarding pedagogical knowledge and academic skills, it is also important to prepare academics for the emotional challenges ahead and develop their emotional resilience to cope with the challenges. Emotion, as an integral part of academics' professional identities (Ursin et al. 2020), can provide useful insights into how academics negotiate tensions between their sub-identities while grappling with personal, institutional, and sociocultural factors. Negative emotions are embedded in identity tensions which help to identify areas of misalignment (Chubb et al. 2017) and directions of efforts. Emotions, both positive and negative, might be driving forces for academics' self-transformation. Positive emotions are particularly valued for sustaining resilience in bridging the sub-identities.

Understanding the process of resilience helps to promote a sense of agency and encourages action rather than focusing on personal limitations regarding identity tensions and challenges. The concept of emotional resilience has enabled us to probe deeply into the emotional nature of academics' professional lives and the roles that multilayered relationships play in supporting the development of their professional identities. Besides, the focus on the reciprocal interaction between emotion and emotional resilience offers a more nuanced and powerful conceptual lens to understand why some academics are able to manage the tensions and integrate their conflictual identities. Our study boils down to an understanding that academics need to cultivate emotional resilience and recognize, value, and attend to emotions in their professional lives to achieve integrated professional identities through a collective endeavor and joint efforts. In this way, academics are more likely to be coherent, highly committed, and motivated in the role, ultimately experiencing overall well-being (Garner and Kaplan 2019).

To best facilitate integrated professional identity development, we suggest that higher education policy makers consider doctoral programs, action research, and social supports as part of a collective endeavor to solve identity tensions. Apart from calling on academics' emotional resilience, we also suggest that policymakers acknowledge the role of emotions in academia (Ursin et al. 2020). The commonly experienced identity tensions and emotional dilemmas should be taken into consideration by policy makers as signals for revisions of current policies. For policy makers and researchers in this field, commonly shared dilemmas such as hectic workloads and insufficient academic training provoke considerable thoughts since if we do not answer them, our use of neoliberal practices may not prove as productive as they might be. The integration of research and teaching cannot be assumed, but has to be actively constructed (Mathieson 2019). 


\section{Appendix}

Table 3 The refined coding system of the participants' professional identities and emotional resilience

\begin{tabular}{|c|c|c|}
\hline Themes & Categories & Sub-categories \\
\hline \multirow[t]{4}{*}{$\begin{array}{l}\text { Professional identity } \\
\text { negotiations }\end{array}$} & $\begin{array}{c}\text { Disheartened } \\
\text { performer }\end{array}$ & $\begin{array}{l}\text { Teacher identity is in tension with researcher identity; unhappy about } \\
\text { both teaching and research }\end{array}$ \\
\hline & $\begin{array}{l}\text { Miserable } \\
\text { follower }\end{array}$ & $\begin{array}{l}\text { Primarily as language teachers; prioritize teaching over research; have } \\
\text { no choice but to do academic research }\end{array}$ \\
\hline & $\begin{array}{l}\text { Strenuous } \\
\text { accommoda- } \\
\text { tor }\end{array}$ & $\begin{array}{l}\text { Have to do research to transit from a knowledge transmitter to a } \\
\text { research-oriented teacher; do a Ph.D. program; conduct action re- } \\
\text { search to integrate the sub-identities }\end{array}$ \\
\hline & $\begin{array}{l}\text { Fulfilled } \\
\text { integrator }\end{array}$ & $\begin{array}{l}\text { Research-oriented teacher; research and teaching not opposite but } \\
\text { connected; fully conscious of the dual responsibilities of being } \\
\text { college English teachers }\end{array}$ \\
\hline \multirow[t]{3}{*}{ Emotional resilience } & Weak & $\begin{array}{l}\text { No sense of achievement; burnout; adapt negatively to the dilemma; } \\
\text { powerless to change; strong negative emotions; external } \\
\text { motivations; passive attitudes; identified no accessible resources to } \\
\text { integrate research and teaching }\end{array}$ \\
\hline & Moderate & $\begin{array}{l}\text { Do not avoid self-doubt or self-dissatisfaction; negative emotions as } \\
\text { agency; recognized available resources }\end{array}$ \\
\hline & Strong & $\begin{array}{l}\text { Intrinsic motivation to do research; linking teaching practice with } \\
\text { research; emotional drive in integrating professional identities; } \\
\text { pinpointed the importance of positive emotions; aware of the harm } \\
\text { of negative emotions; consciously regulate emotions; take initiatives }\end{array}$ \\
\hline \multirow[t]{3}{*}{ Influencing factors } & Personal & $\begin{array}{l}\text { Academics' health; limited time \& energy; self-efficacy; personal } \\
\text { aspirations \& agency; systematic reflection }\end{array}$ \\
\hline & Institutional & $\begin{array}{l}\text { Institutional support; research policy; heavy workload; collegial } \\
\text { pressure; leadership support }\end{array}$ \\
\hline & Sociocultural & $\begin{array}{l}\text { Performativity culture; 'publish-or-perish'; publishing bias; academic } \\
\text { training; peripheral discipline status }\end{array}$ \\
\hline
\end{tabular}

\section{Declarations}

Conflict of interest The authors declare no competing interests.

\section{References}

Arvaja, M. (2018). Tensions and striving for coherence in an academic's professional identity work. Teaching in Higher Education, 23(3), 291-306.

Bai, L. (2018). Language teachers' beliefs about research: A comparative study of English teachers from two tertiary education institutions in China. System, 72, 114-123.

Barkhuizen, G. (2011). Home tutor cognitions and the nature of tutor-learner relationships. In P. Benson \& H. Reinders (Eds.), Beyond the language classroom (pp. 161-174). Palgrave Macmillan.

Barkhuizen, G. (2014). Revisiting narrative frames: An instrument for investigating language teaching and learning. System, 47, 12-27.

Beltman, S., \& Poulton, E. (2019). "Take a step back": Teacher strategies for managing heightened emotions. The Australian Educational Researcher, 46(4), 661-679.

Billot, J. (2010). The imagined and the real: Identifying the tensions for academic identity. Higher Education Research \& Development, 29(6), 709-721.

Carter, S. (2020). Academic identity and the place of stories: The personal in the professional. Springer.

Castelló, M., McAlpine, L., Sala-Bubaré, A., Inouye, K., \& Skakni, I. (2021). What perspectives underlie 'researcher identity'? A review of two decades of empirical studies. Higher Education, 81(3), 567-590. 
Chubb, J., Watermeyer, R., \& Wakeling, P. (2017). Fear and loathing in the academy? The role of emotion in response to an impact agenda in the UK and Australia. Higher Education Research \& Development, 36(3), 555-568.

Cohen, L., Manion, L., \& Morrison, K. (2011). Research methods in education (7th ed.). Routledge.

Dai, H. M., Ju, B., Teo, T., \& Rappa, N. A. (2021). Understanding Chinese female university teachers' intention to pursue a $\mathrm{PhD}$ degree: Some insights from a Chinese university. Higher Education, 81(6), 1347-1366.

Dugas, D., Stich, A. E., Harris, L. N., \& Summers, K. H. (2020). 'I'm being pulled in too many different directions': Academic identity tensions at regional public universities in challenging economic times. Studies in Higher Education, 45(2), 312-326.

Garner, J. K., \& Kaplan, A. (2019). A complex dynamic systems perspective on teacher learning and identity formation: An instrumental case. Teachers and Teaching, 25(1), 7-33.

Henkel, M. (2005). Academic identity and autonomy in a changing policy environment. Higher Education, 49 (1), 155-176.

Huang, Y. T., \& Guo, M. (2019). Facing disadvantages: The changing professional identities of college English teachers in a managerial context. System, 82, 1-12.

Kaasila, R., Lutovac, S., Komulainen, J., \& Maikkola, M. (2021). From fragmented toward relational academic teacher identity: The role of research-teaching nexus. Higher Education. Advance online publication. https:// doi.org/10.1007/s10734-020-00670-8

Kaplan, A., \& Garner, J. K. (2017). A complex dynamic systems perspective on identity and its development: The Dynamic Systems Model of Role Identity. Developmental Psychology, 53(11), 2036-2051.

Kreber, C. (2010). Academics' teacher identities, authenticity and pedagogy. Studies in Higher Education, 35(2), 171-194.

Lee, J. C. K., \& Yin, H. (2011). Teachers' emotions and professional identity in curriculum reform: A Chinese perspective. Journal of Educational Change, 12(1), 25-46.

Mägi, E., \& Beerkens, M. (2016). Linking research and teaching: Are research-active staff members different teachers? Higher Education, 72(2), 241-258.

Mathieson, S. (2019). Integrating research, teaching and practice in the context of new institutional policies: a social practice approach. Higher Education, 78(5), 799-815.

McCune, V. (2021). Academic identities in contemporary higher education: Sustaining identities that value teaching. Teaching in Higher Education, 26(1), 20-35.

McNaughton, S. M., \& Billot, J. (2016). Negotiating academic teacher identity shifts during higher education contextual change. Teaching in Higher Education, 21(6), 644-658.

Nevgi, A., \& Löfström, E. (2015). The development of academics' teacher identity: Enhancing reflection and task perception through a university teacher development programme. Studies in Educational Evaluation, 46, 53-60.

Patton, M. Q. (2015). Qualitative research and evaluation methods (4th ed.). Sage.

Peseta, T., \& Loads, D. (2016). Epilogue: Continuing the conversation. In J. Smith, J. Rattray, T. Peseta, \& D. Loads (Eds.), Identity work in the contemporary university: Exploring an uneasy profession (pp. 195-201). Sense Publishers.

Ravitch, S. M., \& Carl, N. M. (2019). Qualitative research: Bridging the conceptual, theoretical, and methodological (2nd ed.). Sage.

Seidman, I. (2006). Interviewing as qualitative research: A guide for researchers in education and the social sciences. Teachers College Press.

Shams, F. (2019). Managing academic identity tensions in a Canadian public university: The role of identity work in coping with managerialism. Journal of Higher Education Policy and Management, 41(6), 619-632.

Shin, J. C., Arimoto, A., Cummings, W. K., \& Teichler, U. (2014). Teaching and research in contemporary higher education: Systems, activities and rewards. Springer.

Siekkinen, T., Pekkola, E., \& Carvalho, T. (2020). Change and continuity in the academic profession: Finnish universities as living labs. Higher Education, 79(3), 533-551.

Smith, J., Rattray, J., Peseta, T., \& Loads, D. (Eds.). (2016). Identity work in the contemporary university: Exploring an uneasy profession. Sense Publishers.

Spradley, J. P. (1979). The ethnographic interview. Holt, Rinehart and Winston.

Tran, A., Burns, A., \& Ollerhead, S. (2017). ELT lecturers' experiences of a new research policy: Exploring emotion and academic identity. System, 67, 65-76.

Trautwein, C. (2018). Academics' identity development as teachers. Teaching in Higher Education, 23(8), 9951010.

Ursin, J., Vähäsantanen, K., McAlpine, L., \& Hökkä, P. (2020). Emotionally loaded identity and agency in Finnish academic work. Journal of Further and Higher Education, 44(3), 311-325. 
Van Lankveld, T., Schoonenboom, J., Volman, M., Croiset, G., \& Beishuizen, J. (2017). Developing a teacher identity in the university context: A systematic review of the literature. Higher Education Research \& Development, 36(2), 325-342.

van Winkel, M. A., Van Der Rijst, R. M., Poell, R. F., \& van Driel, J. H. (2018). Identities of research-active academics in new universities: towards a complete academic profession cross-cutting different worlds of practice. Journal of Further and Higher Education, 42(4), 539-555.

$\mathrm{Xu}$, Y. (2014). Becoming researchers: A narrative study of Chinese university EFL teachers' research practice and their professional identity construction. Language Teaching Research, 18(2), 242-259.

Yang, S., Shu, D., \& Yin, H. (2021). 'Frustration drives me to grow': Unravelling EFL teacher's emotional trajectory interacting with identity development. Teaching and Teacher Education, 105, 103420.

Zeng, W., \& Fickel, L. (2021). Exploring collective identity of a group of teaching-oriented academics amid research discourse: a Chinese case. Higher Education. Advance online publication. https://doi.org/10.1007/ s10734-021-00728-1

Publisher's note Springer Nature remains neutral with regard to jurisdictional claims in published maps and institutional affiliations. 